Alma Mater Studiorum - Università di Bologna DEPARTMENT OF ECONOMICS

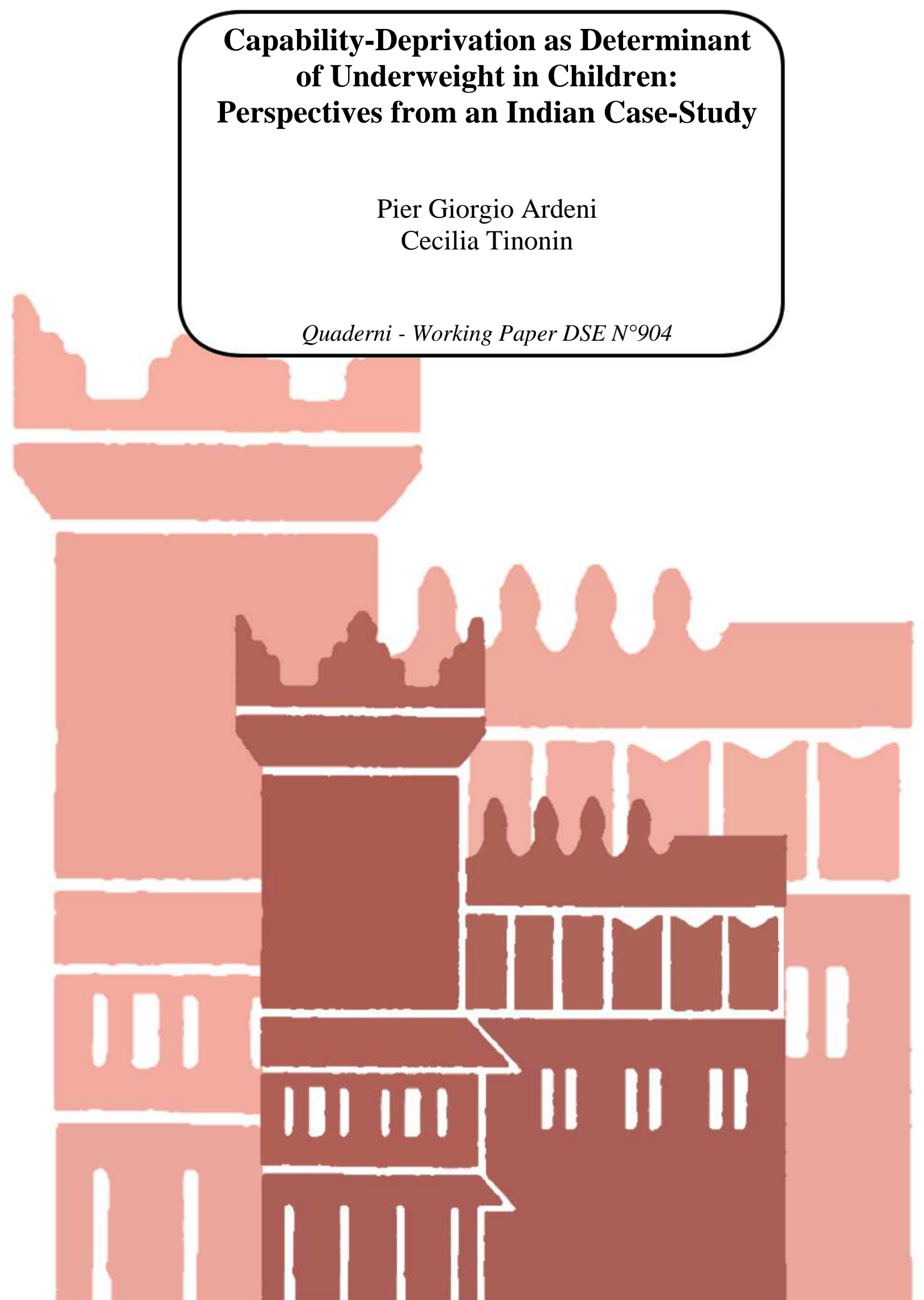




\title{
CAPABILITY-DEPRIVATION AS DETERMINANT OF UNDERWEIGHT IN CHILDREN: PERSPECTIVES FROM AN INDIAN CASE-STUDY ${ }^{1}$
}

\author{
Pier Giorgio Ardeni ${ }^{2}$ \\ Cecilia Tinonin ${ }^{3}$
}

\begin{abstract}
The Capability Approach argues individual advantage should be evaluated in the space of freedom of choice, that is in the space of capability. Yet, empirical applications are hampered by the lack of appropriate data and indicators. This paper aims at providing a reliable and valid indicator measuring deprivation of capability as lack of relative autonomy. Furthermore, it explores its usefulness through an ad hoc case study. Thus, it analyzes the role of women's relative autonomy for the underweight of infants and young children in a rural patriarchal community of India. Inspired by the extended model of care presented in Engle, Menon and Haddad (1999), we estimate regression coefficients in the model by Ordinary Least Square on a probabilistic random sample purposely collected. Results point out autonomy in mobility in a patriarchal society is negatively associated with the nutritional status of children. The norm-based economic framework suggests focusing on 'external capabilities' at the community level for policy interventions aimed at increasing freedom of choice of present and future generations.
\end{abstract}

Keywords: Autonomy, Capability Approach, India, Poverty, Underweight.

JEL Classification: J13, J16, I32.

\section{For an alternative view on well-being}

The emergence of the Capability Approach (hereafter CA), first proposed in the literature by Amartya Sen $(1985,1999)$, has challenged the traditional conceptualization of welfare. In particular, the approach argues in favor of broadening the informational basis on which individual advantage and social welfare are evaluated to include both utility-related information as well as non-utility information, such as those related to rights and liberties. Underlying arguments for a more comprehensive analytical framework are to be found in relations to the shortcomings of utility information. For instance, adaptation of desires due to adverse circumstances biases the hedonistic mental metric as leading principle for public intervention (Clark, 2009). Then, the CA urgently stresses the importance of an evaluative objective metric in the informative space of freedom of choice (Sen, 1985). In particular, four are the constitutive elements of such alternative view, namely functionings, well-being freedom (i.e. capability), agency and agency freedom. Indeed, the social planner is called upon to the ambitious task of assessing simultaneously whether individuals function 'humanely' (e.g. they know how to read and write or are well-nourished) as well as whether they are free to achieve such valuable states of beings and doings. Also, elements of human agency -the freedom individuals enjoy in pursuing their own ethical view of what a good life is- make the analysis even more demanding.

${ }^{1}$ This paper is based on the Doctoral Thesis of Cecilia Tinonin. We gratefully acknowledge financial support for this research from the Department of Statistical Sciences at the University of Bologna through the Marco Polo Fellowship. This study would have not been conducted without the supervision, direction, comments, and share of resources of the Oxford Poverty and Human Development Initiative (OPHI)'s team. In particular, we are extremely grateful to Sabina Alkire, José Manuel Roche and Sebastian Silva-Leander for their precious guidance. Also, we are grateful to Kimberly Fisher at the Centre for Time Use Research (CTUR) and to Vikas Rawal at the Centre for Economic Studies and Planning (CESP) at Jawaharlal Nehru University (JNU). Furthermore, Vaibhav Tripathi, Kirti Shukla, Priyanka Singh, Vikram Singh provided a crucial research support. Moreover, the paper greatly benefited from comments made by participants at the following seminars and conferences: Centro Studi sul Genere e l'Educazione (CSGE) Lunch Seminar, University of Bologna; Oxford Poverty and Human Development Initiative (OPHI) Lunch Series Seminar, University of Oxford; Human Development and Capabilities Association (HDCA) Conference, The Hague; the International Statistical Institute's (ISI) Conference, Dublin; the Social Economy and Civil Society Workshop of Young Economists, University of Bologna. The usual disclaimer applies.

${ }^{2}$ Corresponding author: Pier Giorgio Ardeni, University of Bologna, Dipartimento di Scienze Economiche, Strada Maggiore 45, 40145, Bologna, Italy. E-mail: piergiorgio.ardeni@unibo.it

${ }^{3}$ Cecilia Tinonin, University of Bologna, Dipartimento di Scienze Economiche, Strada Maggiore 45, 40145, Bologna, Italy. E-mail: cecilia.tinonin@unibo.it 
Although the Capability Approach has been widely recognized as an outstanding contribution to Economic Theory (Nobel Prize, 1998) the measurement of its main tenets is still a far-reaching objective. ${ }^{4}$ Thus, the widespread emergence of composite indicators, for instance in the field of development economics or quality of life studies, is still limited to the space of achievements and outcomes. Conceptualizing well-being in terms of capability means, however, to focus the attention on two constituent aspects of the concept, namely opportunityfreedom and process-freedom (Sen, 2002). In particular, the former is appointed to assess whether an alternative for choice does exist, whereas the latter considers whether the decision-making process is unrestricted from external interferences. Furthermore, difficulties in availability of capability-oriented data is strictly linked to the issue of 'measuring without a theory'. Indeed, the CA does not proposes any predictive theoretical insights nor any elaborated formalization of its main pillars. Yet, the intrinsic nature of the approach, which roots into a profound dialogue among disciplines, calls upon the identification of specific case-studies capable of stressing its crucial importance in fostering human progress as well as the overall achievement of the Millennium Development Goals (Alkire, 2005b).

The analysis of determinants of underweight in children within a capability-related conceptual framework fits such purpose. For undernutrition in children is a detrimental multiplier with respect to the potential for human flourishing. Indeed, when it occurs during the first three years of lifespan, it negatively and irreversibly affects both cognitive and motor development (Alderman, 2006). As a consequence, development programs aimed at eradicating such plague are the most effective in fighting the vicious circles of poverty (World Bank, 2006). Furthermore, the theoretical model on the determinants of the phenomenon identifies three level of causality, namely basic determinants (i.e. economic and political conditions of the country), underlying determinants (i.e. household characteristics in terms of food security, hygiene and status of women) and individual determinants (i.e. lack of dietary intake) (Engle, Menon and Haddad, 1999). When such model applies to India, the observational unit behaves as an outlier. Despite sustained economic growth and simultaneous decrease of monetary poverty, the country indeed hosts among the highest percentage of underweight children in the world (Gragnolati et al., 2005). ${ }^{5}$ Then, the gravity of the phenomenon is such that Swaminathan (2009) have labeled it as the Indian Development Paradox.

In the attempt to shed light on reasons behind the persistence of undernutrition despite of substantial economic growth, a specific focus on the status of women has been highlighted as the major area of concern (Smith and Haddad, 2000; Kumar, 2007; Ramachandran, 2007). For instance, according to the Human Development Report (2013), despite India ranks higher in terms of the Human Development Index, its Gender Inequality Index is lower with respect to less successful neighboring economies, such as Pakistan and Nepal. ${ }^{6}$ Furthermore, the need for assessing status of women goes beyond its measurement in traditional informational spaces, such as education, health or material living standards (Smith and Haddad, 2001). ${ }^{7}$ Rather, the attention should be placed on the real opportunities they have for improving their own lives as well as the existences of future generations. Simultaneously, embracing the CA's perspective for the analysis of health-related concepts has been increasingly advocated in the field of health economics (Cookson, 2005; Coast et al., 2008; Law and Widdows, 2008) as well as in gender-related studies (Agarwal et al., 2005).

The aim of this paper is, therefore, to provide an ad-hoc informational basis to contribute to the operationalization of the CA. In particular, the primary data collection does not limit itself on merely gathering information on 'missing dimensions' of poverty, such as those related to deprivation of capability (Alkire, 2007) but it also focuses on the identification of a particular case-study capable of underlining the importance of adopting a broader analytical framework for the conceptualization of well-being as well as of providing insights for its further development in a bottom-up fashion.

${ }^{4}$ For a recent contribution aiming at the further theoretical development of the approach, please see Silva-Leander, S. (2012) Revealed Meta-Preferences: Axiomatic Foundations of Normative Assessments in the Capability Approach, OPHI Working Paper No. 48, Oxford Poverty \& Human Development Initiative, University of Oxford, Oxford.

5 According to Haddad (2009) at the micro-level, international evidence shows that for every 3-4 per cent increase in per capita income, undernutrition rates, as measured by underweight rates, should decline by 1 per cent. Furthermore, for references on decrease of poverty in India, please see Deaton A. - Drèze J. (2009), Food and Nutrition in India: Facts and Interpretations, in Economic and Political Weekly, vol. 44, pp. 42-65.

${ }^{6}$ The Human Development Index is a summary measure of key dimensions of human development. It measures the average achievements in a country in three basic dimensions of human development: a long and healthy life, access to knowledge and a decent standard of living. The Gender Inequality Index is a composite measure reflecting inequality in achievements between women and men in three dimensions: reproductive health, empowerment and the labor market. For further references, please see: United Nations Development Report (2013), Human Development Report 2013. The Rise of the South: Human Progress in a Diverse World, New York.

${ }^{7}$ For instance, based on the analysis of the National Family and Health Survey-III, Joe et al. (2009) identify a significant proportion of underweight children living in households where the mother has completed more than 12 years of education. Also, more than 20 per cent of underweight children lived in household belonging to the highest quintile of the wealth distribution. 
The paper, therefore, contributes to the growing empirical literature on the multidimensionality of poverty. In particular, its value added consists in shedding light on seldom collected information, such as those related to capabilities. Moreover, it steps forward by providing an empirical application to test whether such information are statistically relevant for the identification of underlying determinants of underweight in infant and young children. In addressing such issue from the CA's perspective, the particular functioning of the young child to be well-nourished is assumed to be dependent on the behavior of the mother as usually identified as the main caregiver (Osmani and Sen, 2003). In particular, conditional on availability of resources for care and food security, the autonomy of the mother to move around freely in the community is supposed to be of crucial interest because it lays the basis for her ability to take the child to a doctor or to gain those key information necessary to the well-nourishment of children.

The paper is, therefore, structured as follows. Section 2 lays out the conceptual framework for measuring deprivation of capability as lack of autonomy. Section 3 presents the methodology employed for primary data collection, whereas Section 4 presents the characteristics of the sample. Section 5 assesses the reliability as well as the validity of the capability-related indicator. Section 6 provides descriptive statistics of variables and indices entering the analysis, whereas Section 7 empirically tests the statistical significance of the association between autonomy and the nutritional status of children controlling for traditionally confounding determinants, such as the wealth of the household and characteristics of the mother. Section 8 discusses final results and concludes.

\section{Deprivation of capability as lack of autonomy}

The increasing use of psychological components in the explanation of human behavior in mainstream economics applies also to alternative perspectives belonging to different paradigms. As a norm-based conceptual framework, the CA argues in favour of establishing external correspondences between choice on the one hand as well as values, aims and goals on the other hand (Sen, 2002). In particular, Sen (1994) discusses against any a priori imposition of internal consistency of choice in modelling human behaviour and in favour of a 'contextdependent parametric variations in the characterization of rational choice'. A crucial implication of such formulation relates to the inclusion of ethical considerations as motivation behind choice, which takes on the form of introducing buman agency into economic theory (Sen, 1985). In particular, the concept of agency refers to the ability to purse one's goals, aim and obligations, among which well-being could be one among several. As result, the approach requires a widened informational basis accounting for well-being (achieved functionings), the capability to function (well-being freedom), agency (the moral conception of the good) and agency freedom (the freedom to pursue one's own moral conception) individuals have in choosing a particular vector of functioning within a capability set.

The measurement of agency, conceptualized in terms of autonomy, effective power and other-regarding goals, has been originally proposed in Alkire (2005) and further developed in Ibrahim and Alkire (2007), Alkire $(2007,2008)$ and Alkire and Chiappero-Martinetti (2008). Such framework builds upon sound theoretical bridges between the CA and the Self-Determination Theory (hereafter SDT) developed by Deci and Ryan (2000) in the field of positive psychology. The SDT is an empirically-based theory of human motivation and personality, which 'concerns the perceived locus relative to the person of variables that causes or give impetus to behavior' (Ryan and Connell, 1989) and which 'views the issue of autonomy as a key to understanding quality of behavioral regulations' (Ryan and Deci, 2006).

Whereas autonomy refers to true self-regulation (i.e. self-governance as reflected in its etymology 'rule by the self'), motivation concerns 'energy, direction and persistence defining aspects of intention and activation behind behavior'. In particular, SDT classifies behavioral motivations into five modalities standing on an underlying continuum of autonomy. The prototype of self-determined and highly autonomous behavior is intrinsically motivated, which refers to 'the inherent tendency to seek out novelty and challenges, to extend and exercise one's capacity, to explore and to learn' and 'doing of an activity for the inherent satisfaction of the activity itself. At the other hand of the continuum there is amotivation, which refers to 'the state of lacking the intention to act' and indicates just going with the motions. According to SDT, amotivation results from 'not valuing an activity, not feeling competent to do it or not expecting it to yield the desire outcome'.

In between such two extremities (i.e. amotivation and intrinsic motivation), extrinsic motivations vary according to different degrees of autonomy in their regulation. Thus, the least autonomous is behavior externally regulated, such as behavior 'performed to satisfy an external demand or reward contingency. Individuals typically experience externally regulated behavior as controlled or alienated, and their actions have an external perceived locus of causality'. A second type within the range of extrinsic motivation is introjected regulation, which 'involves taking in a regulation but not fully accepting it as one's own. It is a relatively controlled form of regulation in 
which behaviors are performed to avoid guilt or anxiety or to attain ego enhancements such as pride'. Furthermore, identified regulation 'reflects a conscious valuing of a behavioral goal or regulation, such that the action is accepted or owned as personally important'. Lastly, integrated regulation is closely related to intrinsic motivation. Yet, it concerns actions aimed at achieving separable outcomes from the inherent enjoyment of the activity itself. On the basis of such conceptual framework, we have conducted an empirical investigation to assess the underlying autonomy of women in moving around freely in their own community.

\section{Methodology for primary data collection}

Among the methodological constraints empirical investigations face when adopting the capability approach, a major challenge is the availability of data collected in line of its tenets (Comin, et al., 2008). Based on a mapping study, conducted by the Government of India in collaboration with the World Bank, which ranks districts by a composite indicator measuring anemia in women and undernutrition in children, we identified the district of Baghpat in Uttar Pradesh, India, as the geographical area where to conduct a primary data collection. ${ }^{8}$ The district of Baghpat -known in Hindi as 'the Land of Tigers'- is situated in the Northern State of Uttar Pradesh. The local economy is defined by a large primary sector particularly skewed toward the production of sugarcane, which greatly benefits from its proximity to Yamuna and Ganges, main Indian rivers. Moreover, among 315 villages in the area, the survey design purposely selected the village of Sankraud as its relatively medium size could allow to detect variations in individual characteristics. According to the Indian Census (2001), the total population of the village was $5,937.9$

The survey was carried out in 2010, after three months of expert and qualitative interviews, field visits, logistic set-up, enumerators training, translation of the survey instruments and questionnaire pre-testing. Due to possible sources of bias in existing sampling frames, the sampling methodology foresaw drafting an ex-novo list to record all households where a child aged $0-3$ years was a member. Then, we implemented a proportional stratified random sample by using mohallas (local administrative units) as strata and by assuming each strata is homogenous in terms of wealth and religion. From each mohalla, a simple random sample was drawn maintaining a proportion between sampling and sampled units. Under budgetary constraints, the total sample size was 127 households out of 273 households recorded in the sampling frame.

In terms of methodology for data collection, particular care was paid to rule out any possible source of external influence on capability-related data. ${ }^{10}$ We have, therefore, designed two different survey instruments, namely the Household Questionnaire (hereafter HQ), which covered resources-based information, and the Child and Mother Questionnaire (hereafter CMQ). In particular, the CMQ included the Oxford Poverty and Human Development Initiative (hereafter OPHI)'s Module on Agency and Empowerment as well as a 24-hours recall Time-Use Diary designed after the Indian Time-Use Survey conducted in 1998/1999. Furthermore, the motherin-law and other members of the household were identified as main respondents for the HQ in order to allow the mother of the child to be alone in a separate room with a female enumerator when answering to sensitive questions. Main methodology for data collection was face-to-face (self-reporting) at home interview, whereas anthropometric measurement has been undertaken by trained enumerators through a portable weight scale (Docbel Braun, Weighing Scale) and a portable height scale. Also, we had welcomed suggestions from the Nutrition Bureau of India in order to minimize measurement error in anthropometry. Accordingly, the Ethical Code for implementing anthropometric survey in India requires measurement to take place during the spring season, when the average temperature is equal to 42 degrees Celsius.

8 Tool Book ICDS-IV Project (2008-09 to 2012-2013) Central Project Management Unit, Ministry of Women and Child Development Service, Government of India. Using data from the District Level Household Survey-II (2002/04), the World Bank and the Integrated Child Development Service (ICDS) (2008) ranked first the district of Baghpat on the basis of a composite indicator, which accounts for low nutritional status of children below six years (NCHS standard <-2SD) and anemia level among pregnant women age 14-44 years.

${ }^{9}$ In particular, total male population was 3,197 whereas total female population was 2,740.

${ }^{10}$ For instance, at the field level the overall survey team divided in two groups. Each group consisted of a female and a male enumerator. Every team interviewed one household at a time, so that in an hour two households were interviewed. Furthermore, questionnaires were field-checked by the researcher, who was present during the entire data collection. If inconsistency were found, the team went back to the selected household and clarified doubts. Also, data entry was performed by enumerators after the survey ended so that if additional inconsistencies were to be found, it would had been possible to visit the village to clear them out. However, systematic data cleaning was carried out and discrepancies were solved only with reference to the questionnaire. 


\section{Characteristics of a patriarchal sample}

The survey collected information on a sample of 127 households and on the corresponding 136 mothers of children aged 0-3 years living in such households. ${ }^{11}$ Only one missing case was registered because of the refusal to cooperate to the survey due to a lack of financial incentives. In line with the characteristics of the area, the overall sample covers 51 households declaring to be Muslim (40\%), whereas the remaining 76 declaring to be Hindu $(60 \%)$. Furthermore, 96 households declared to belong to a Other Backward Caste (hereafter OBC) (75\%), 20 households (16\%) to belong to Scheduled Caste (hereafter SC) and $12(9 \%)$ to the higher General caste (hereafter GC). With regards to the family structure, the average household size is 7.95 individuals $(\mathrm{sd}=3.31)$ within a range from 3 to 24 individuals. In terms of the dependency ratio (hereafter Dratio), the mean value is $0.40(\mathrm{sd}=0.16)$ within a range from 0.1 to 0.7 .12 Moreover, the age range of individuals in the sample is 0 to 77 years, with an average age equal to 22.42 .

The survey design drawn from the Living Standard Measurement Survey, conducted by the World Bank in Bihar and Uttar Pradesh in 1998/99, the categorization of employment status, which was collected at the individual level within every single household. At glance, all women declared to be involved in household duties as primary occupation. At a deeper investigation, only 23 women declared to be involved also with a secondary occupation. ${ }^{13}$ In terms of education, 35\% of female respondents declared not to be able to read and write, whereas only $3 \%$ to know basic reading and writing without having attended formal schooling. The median is middle school, which $30 \%$ of respondents completed. Furthermore, 17 respondents reported they had achieved a high level of education, such as intermediate (8\%), Bachelor (4\%) and Master (2\%) Degrees.

Contrary to what commonly assumed, the measurement of age in rural communities in developing countries is a challenge. For instance, out of 136 females entering the sample, 115 women declared their age, which mean values is 25.05 years $(\mathrm{sd}=3.62)$. Therefore, the survey collected several age-related information, such as age-atmarriage, how long the respondent has been living in the community and whether she moved in the community when she got married. As a result, the mean value for age at marriage (hereafter agem) is equal to 18.55 years (s.d=2.56) pointing out the persistence of early childhood marriage. Indeed, the distribution of individuals according to age at marriage reports $33 \%$ of cases getting married before the legal age. Moreover, a new indicator of age, labeled aget, is constructed on the basis of the age-at-marriage plus the number of years the woman has been living in the community conditional to whether she moved to the community at the moment of marriage. Such reasoning appear to be meaningful considering 132 women moved to the village when they got married, whereas only 3 have already been lived there. ${ }^{14}$ Furthermore, women have been living in the area on average for the past 7.05 years.

An important characteristics of the sample as well as of the geographical area as a whole regards the patriarchal structure governing social interactions. ${ }^{15}$ In particular, the analysis of the structure of the decisionmaking process within the household points out women have great control only on those decisions related to household duties, whereas for other important spheres of life, such as being employed, visiting a doctor, moving around the community, enrolling children at school, the power lays in the hands of the husband and the motherin-law (Table 1). Furthermore, indicators measuring subjective well-being point out female respondents were on average really happy. Indeed, $90 \%$ of respondents declared to be very satisfied or satisfied with their lives, all things considered. Interestingly, none replied to be very discontented. For some may argue happiness is not the ultimate end of life, they were also asked whether they would like to change something in their existences. Surprisingly, 86 women had provided positive responses, in particular with regards to their education, health, participation to the labor market and living conditions. Yet, when asked who they think would contribute the most to those transformations they wish to undertake, only two women reported they could have a say for those changes to occur.

\footnotetext{
11 The presence of nine joint families, which by definition eat and share resources under the same dwelling unit, explains the difference between the number of respondents for the HQ and the number of respondents for the CMQ.

12 The dependency ratio is the ratio between the number of children below 15 years living in the household and total number of people living in the household.

${ }^{13}$ In particular, 12 women declared to be occupied in their own farm activity, 10 to be casual labor and 1 to be retired and too old to participate to the labor market. Furthermore, type of employment women are involved in, either remunerative or related to household duties, appear not to be strictly related to education's achievement.

${ }^{14}$ Computation of aget yields a new variable which ranges from 17 to 40 years with a mean value equal to 25.75 (sd=3.93). On average, the difference between age reported and age calculated on the basis of further information is -0.42 years.

15 As Uberoi (2009) states, a patriarchal society is one in which descent and group placement, inheritance and succession are all 'harmoniously' in the male line, where post-marital residence is patrilocal and where family authority resides with senior male members'.
} 
Table 1: Who in your household does decide on the following? ( $\mathrm{n}=136)$

\begin{tabular}{|c|c|c|c|c|c|c|c|}
\hline & Work & See a doctor & Mobility & Child doctor & $\begin{array}{c}\text { Household } \\
\text { work }\end{array}$ & Schooling & $\begin{array}{c}\text { Spending } \\
\text { money }\end{array}$ \\
\hline $\mathrm{Me}$ & 0.7 & 2.2 & 0.7 & 4.4 & 81.5 & 27.4 & 5.2 \\
\hline My husband & 71.9 & 62.2 & 64.4 & 59.3 & 3.0 & 43.0 & 57.8 \\
\hline Mother-in-law & 11.1 & 23.0 & 20.0 & 22.2 & 11.1 & 15.6 & 17.8 \\
\hline Me and my husband & 4.4 & 4.4 & 3.7 & 5.9 & 0.7 & 4.4 & 9.6 \\
\hline Head of the household & 8.9 & 5.9 & 8.1 & 6.7 & 3.0 & 7.4 & 8.1 \\
\hline The whole family & 3.0 & 2.2 & 3.0 & 1.5 & 0.7 & 2.2 & 1.5 \\
\hline Total & 100 & 100 & 100 & 100 & 100 & 100 & 100 \\
\hline
\end{tabular}

\section{Constructing validity for a capability-related indicator}

To measure autonomy in the domain of mobility, the survey instrument asked respondents why they do so when they move around the community or stay inside the house. Possible reasons were as follows: (1) "No control": I am not able to go out at all or I have to work. I have no option of staying at home (hereafter MOAG1); (2) "External regulation": I need to have permission in order to go out (hereafter MOAG2); (3) "Introjected regulation": I need to be careful when I go out so that people do not speak badly about me (hereafter MOAG3); (4) "Identified regulation": If it is important to go out I will do so no matter what (hereafter MOAG4); (5) "Integrated regulation": If I want to go out (or to stay in for that matter) I am able to think about it and freely decide to do what seems the best. There are no restrictions on me in this respect (hereafter MOAG5). ${ }^{16}$ Semantic response items varied in degrees of truthfulness (i.e. not at all true, not very true, somewhat true, completely true).

As result, among respondents, $87 \%$ needed permission in order to go out and $86 \%$ declared in need of being careful when they go out so that people do not speak badly about them. Only $19 \%$ of informants reported that if it is important to go out they would do so, no matter what. Furthermore, $48 \%$ of women declared not at all true that if they want to go out they are able to think about it and freely decide to do what seems the best.

A fundamental step before data analysis is the assessment of the quality of data through tests of reliability and validity. In particular, the concept of reliability refers to whether data are consistent through repeated measurement. Thus, it is a statistical measure of the reproducibility or stability of the data gathered by the survey instrument. When reliability tests aim at verifying whether different items measure the same underlying concept in a single sample at one point in time, internal consistency methods are applied (Abell, et al., 2009). Among different methods, the coefficient $\alpha$ (Guttman, 1945; Cronbach 1951) is the most commonly utilized method (Abell, et al., 2009). The coefficient $\alpha$ evaluates the reliability of a set of measures by examining the consistency with which people answer each item in the set. Thus, the Cronbach's coefficient alpha is often calculated to determine the extent of homogeneity. It varies from 0 to 1 , with higher value indicating higher reliability. ${ }^{17}$ With regards to the present study, the internal consistency Cronbach's alpha coefficient of the scale indicates quite an acceptable reliable structure $(\alpha=0.59)$ (Table 2). ${ }^{18}$

To strengthen the evaluation of the internal consistency of the scale, we also analyze the degree and structure of association among items. As result, having no option of freely going out is positively and statistically significantly associated with being in need of asking permission to go out and also with being in need to be careful when one goes out so that people do not speak badly. Furthermore, having no options is also negatively and significantly associated with being able to go out if it is important and also with having no restrictions in this respect. Furthermore, external pressure is positively and significantly associated with introjected regulation, indicating the need of asking permission to go out in relation to punishment from the community if a woman moves around freely without permission. On the other hand, having permission to go out (external pressure) is negatively associated with identified and integrated motivations (i.e. higher autonomous motivations). Moreover,

16 The OPHI Module on Agency and Empowerment investigates extrinsic motivations behind choice in a particular domain. Therefore, it rules out any attempt at measuring directly intrinsically motivated activities, namely those endorsing the highest form and substance of autonomy.

17 A commonly accepted standards for its evaluation is 0.60 or greater values (Abell, et al., 2009).

18 In their seminal paper, Ryan and Connell (1989, p. 748) provided the statistical justification for assessing reliability on a scale of items differing in degree and in kind -such as in the OPHI's scale- on the basis of the continuum of autonomy of extrinsic motivation, as follows: "We then propose that an appropriate model for describing perceived locus of causality for one's own actions conforms to a simplexlike or ordered correlation structure. The simplex concept is derived from Guttman's (1954) radix theory, which describes ordered relations between correlated variables. In a simplex variables are ordered in terms of complexity or conceptual similarity, such that those deemed more similar correlate more highly than those that are hypothetically more discrepant. When arranged in a matrix, a perfect simplex model evidences its largest correlation along a main diagonal, and these increasingly taper off as one moves away from that diagonal. Guttman argued that a simplex model reflects an ordered arrangement along a parameter of variables that also embody qualitative differences". 
Table 2. Internal consistency Reliability for autonomy in mobility- Cronbach's alpha coefficient values ( $\mathrm{n}=134$ )

\begin{tabular}{ll}
\hline \hline Cronbach's alpha (MOAG1, MOAG2, MOAG3, MOAG4, MOAG5) & 0.59 \\
Cronbach's alpha (MOAG2, MOAG3, MOAG4, MOAG5) & 0.54 \\
Cronbach's alpha (MOAG1, MOAG4, MOAG5) & 0.60 \\
Cronbach's alpha (MOAG4, MOAG5) & 0.66 \\
\hline
\end{tabular}

Table 3. Kendall's tau b coefficient for autonomy in mobility $(\mathrm{n}=134)$

\begin{tabular}{|c|c|c|c|c|c|}
\hline & No control & External & Introjected & Identified & Integrated \\
\hline No control & 1 & & & & \\
\hline External & $0.23^{* *}$ & 1 & & & \\
\hline Introjected & $0.19 * *$ & $0.26^{* *}$ & 1 & & \\
\hline Identified & $-0.21 * *$ & $-0.19 *$ & -0.05 & 1 & \\
\hline Integrated & $-0.21 * *$ & $-0.19 *$ & $-0.15^{*}$ & $0.48^{* *}$ & 1 \\
\hline
\end{tabular}

Note: ${ }^{*} p$-value $<0.05 ; * * p$-value $<0.01$

Table 4. Correlation Matrix between RAI and Time-Use activities

\begin{tabular}{|c|c|c|c|c|c|c|c|c|c|}
\hline & RAI & Sleep & Relax & Eat & Weeding & Cooking & Cleaning & Pchildcare & Travel \\
\hline RAI & 1 & & & & & & & & \\
\hline Sleep & 0.07 & 1 & & & & & & & \\
\hline Relax & $-0.14^{*}$ & -0.09 & 1 & & & & & & \\
\hline Eat & -0.13 & $0.19^{* *}$ & -0.12 & 1 & & & & & \\
\hline Weeding & -0.26 & -0.28 & 0.20 & -0.28 & 1 & & & & \\
\hline Cooking & $-0.14^{*}$ & $-0.22^{* *}$ & -0.08 & $-0.23 * *$ & $-0.48^{*}$ & 1 & & & \\
\hline Cleaning & $0.15^{*}$ & 0.09 & $-0.25 * *$ & 0.09 & $-0.67 * *$ & 0.02 & 1 & & \\
\hline Pchildcare & $0.20^{*}$ & -0.08 & -0.03 & -0.14 & 0.13 & -0.03 & 0.16 & 1 & \\
\hline Travel & 0.17 & -0.04 & -0.05 & -0.29 & -0.09 & -0.15 & -0.34 & 0.15 & 1 \\
\hline
\end{tabular}

Note: ${ }^{*} p$-value $<0.05 ; * * p$-value $<0.01$

deciding to go out if it is important is positively and significantly associated with having no restrictions in this regard (Table 3).

Having assessed the reliability of the scale, we then follow standards procedures for constructing an indicator of relative autonomy in the domain of mobility (hereafter RAI). As result, it ranges between -9 to 6 with a median value equal to -6 . Taking the value of zero as an arbitrary cut-off point, women overall do not report a high level of autonomy with regards to their choices related to their mobility. Furthermore, in order to test its validity, we explore simple correlations between RAI and a set of variable of interest (Table 4). First, we look at the association between time-use activities and the indicator of autonomy. As result, autonomy in mobility is negatively correlated with hours spent in relaxing and in cooking, which are activities usually undertaken within the dwelling unit, whereas it is positively correlated with hours dedicated to the physical care of the child and to the cleaning the household, which to a certain extent also involved moving in the proximity of the dwelling unit. Most interestingly, RAI is negatively correlated with the Body Mass Index (hereafter BMI) of respondents.

\section{Variables and indices}

To measure the specific functionings of the child of being well-nourished, that is the dependent variable, the sample covers information on 149 children aged $0-3$ years, of which $71(48 \%)$ male and $78(52 \%)$ females. In particular, weight has been recorded for 143 children and its mean value is 8.68 kilograms. Height has been measured for 130 children with a mean value of 75.32 centimeters. Third is age in months which averages at 17.41 months. ${ }^{19}$ In order to construct anthropometric indicators, data on length/height and weight are transformed into z-scores using the software World Health Organization (WHO) Anthro V.3.1.0 (2010).20

${ }^{19}$ Being the indicator particularly sensitive to possible measurement errors in assessing the age of the child, we adopted FAO (2008) Guidelines for Estimating the Month and Year of Birth of Young Children. Accordingly, we computed age in months from the date of birth to the date of the survey.

20 The software is freely downloadable at www.who.int/childgrowth/software/en/ 
Table 5: Distribution of anthropometric indicators of children aged 0-3 years for the sample, Uttar Pradesh (UP) and India, (\%)

\begin{tabular}{|c|c|c|c|}
\hline & Sample & $\begin{array}{c}\text { UP } \\
(2005-06)\end{array}$ & $\begin{array}{c}\text { India } \\
(2005-06)\end{array}$ \\
\hline Underweight & 35.5 & 41.6 & 40.4 \\
\hline Wasting & 19.5 & 19.5 & 22.9 \\
\hline Stunting & 47 & 52.4 & 44.9 \\
\hline BMI-for-age & 16.5 & - & - \\
\hline Severe underweight & 15.9 & - & 15.8 \\
\hline Severe wasting & 6.5 & - & 7.9 \\
\hline Severe stunting & 24.8 & - & 22.0 \\
\hline Severe BMI-for-age & 16.5 & - & - \\
\hline
\end{tabular}

Note: Underweight, Wasting, Stunting and BMI-for-age refers to the percentage of children whom Z-scores are below 2 standards deviation from the reference value. Severe underweight, wasting, stunting, and BMI-for-age refer only to the percentage of children whom Z-scores falls below 3 standard deviations from the reference value. The same applies for statistics at the State and National level. Data for India are released on the website of the Indian Planning Commission. Data on Uttar Pradesh (UP) are from the NHFS-3 fact sheet for UP.

According to the WHO Child Growth Monitoring (2006), z-scores measures the distance of an individual observation from the median of the reference population divided by the standard deviations of that reference population. On such basis, four anthropometric indicators are computed: weight-for-age (hereafter WAZ), weight-for-height (hereafter WHZ), height-for-age (hereafter HAZ) and BMI-for-age (hereafter BAZ), which all point out the presence of undernutrition in the sample (Table 5). Among the four anthropometric indicators computed, we select weight-for-age (hereafter WAZ) following several scholars (Deaton and Drèze, 2009; Kumar, 2007) highlighting that if a single summary indicator is to be used, weight-for-age would claim special attention in economic analysis'. Indeed, underweight children are also likely to be stunted and wasted. Furthermore, the dependent variable WAZ ranges from -5.55 to 3.51 and it is free from implausible values. ${ }^{21}$ Moreover, underweight is recorded for 35.5\% (49 observations) of children -that is the percentage of children whose $z$-scores are below two standard deviations from the median in the population of reference- with a peak registered in the age group 12-24 (42.9\%), whereas severe underweight affects $15.9 \%$ of children with the major incidence in the age group 24-36 (24.4\%) (percentage of children whose z-scores are below three standard deviations from the median in the population of reference). The mean value for the sample is $-1.49 \mathrm{z}$-score (sd=1.55). In order to construct the dependent variable we rule out those 5 cases for which WAZ was above two standards deviations (i.e. overweight cases). ${ }^{22}$

With regards to anthropometry for female adults, weight was recorded for 104 cases. The mean value is 50.66 kilograms (sd=8.31) and ranges between 34.2 to 76.2 kilograms. Also, height is recorded for 98 cases and its mean value is 153.63 centimeters $(\mathrm{sd}=5.99)$ within a range from 139 to 172 centimeters. Accordingly, the Body Mass Index (hereafter BMI) is constructed only for those cases for which both weight and height are available. The BMI for female adults ranges between 14.1 and 30.44 and it averages at $21.27(\mathrm{sd}=3.24)$. Among them, 19 cases are characterized by a low BMI and 12 cases by being overweight. Turning to male adults, weight is recorded for 92 observations and it averages at 51.65 kilograms ( $\mathrm{sd}=9.29)$ within a range from 34.2 to 78.7 kilograms. Thus, a slight gender bias favoring males is recorded in adults population. Furthermore, height is recorded for 82 observations and it averages at 155.17 centimeters $(\mathrm{sd}=8.29)$ within a range from 139 to 178 centimeters. As result, the BMI for male adults ranges from 15.12 to 30.44 and it averages at 21.10 ( $\mathrm{sd}=3.26$ ). The distribution of BMI in male adults points out 18 cases being underweight and to 11 cases being overweight. A positive and highly statistically significant correlation is found between the mother and father's BMI $(0.93$; $p$ value $=0.000)$.

To empirically measure wealth in the absence of information on income and consumption, we follow Filmer and Pritchett (2001) who have proposed to construct a linear index from assets' ownership indicators and household characteristics. Therefore, we perform a Principal Component Analysis on five variables, that are number of bigha of land the household owns, number of livestock converted in Tropical Livestock Unit (TLU), number of rooms in the dwelling unit, adjusted monthly agricultural value and number of assets in the household (Table 6). ${ }^{23}$ Then, we extracted one component, labeled wealth, that explains $62 \%$ of total variability.

\footnotetext{
21 According to WHO Standards (2006) implausible values for waz are observation below -6 and observation above 5.

22 Yet, regression diagnostics are not alternated if such cases are included.

23 Bigha is a unit of measurement usually adopted for quantifying area of land in South Asia, particularly in Nepal, Bangladesh and some States in India. Yet, bigha is not a part of an unit's nomenclature. According to enumerators, in the state of Uttar Pradesh 1 acre corresponds to 0.652 bigha. The sample mean value for land owned is 12 bigha (sd=20.90). Furthermore, by including the number of
} 
Furthermore, the loadings of the first principal component associated to the standardized resources-related variables are, as follows: 0.482 (lando), 0.445 (housingasst), 0.451 (hroom), 0.427 (avalue3), 0.427 (lstok). Moreover, values of wealth vary in a range from -2.04 to 6.71 .

When investigating preliminary correlation between our dependent variable and potential covariates, we find war is negatively correlated with the autonomy of the mother to move freely around the community and positively with the wealth index of the household (Table 7). Furthermore, the dependent variable is correlated positively with the years of schooling of the mother (edu) and with her age at marriage (magem), whereas it is negatively correlated with the dependency ratio of the household. In terms of correlations among covariates, the highest correlation is to be found between the wealth index and the years of schooling of the mother and with her age at marriage. Thus, better standards of living measured in the space of resources are associated with positive characteristics of maternal health, such as her normal height (mheight), legal age at marriage and low dependency ratio. On the other hand, such covariates are negatively associated with the autonomy of the mother to move freely in the community. Such results preliminary suggest that in the patriarchal community women with higher economic status tend to be characterized by better socio-economic indicators. Yet, they simultaneously tend to show a more subtle form of deprivation, that is poverty as lack of freedom of choice. On the opposite side, the few women reporting an empowered profile are also those who suffer from material deprivation.

Table 6. Summary statistics for indicators of assets' ownership

\begin{tabular}{lllcccc}
\hline \hline Assets Indicators & $\begin{array}{c}\text { Unit of } \\
\text { observation }\end{array}$ & Type & $N$ & Range & Mean & Sd \\
\hline Land owned & Household & Numeric & 127 & $0-80$ & 10.38 & 19.43 \\
Livestock (TLU) & Household & Numeric & 127 & $0-6$ & 1.54 & 1.60 \\
Rooms & Household & Numeric & 127 & $1-11$ & 3.69 & 2.32 \\
Monthly agricultural & Household & Numeric & 124 & $0-13.020$ & 1.007 & 2.154 \\
value (Rp.) & & & & $0-18$ & 5,73 & 3.67 \\
Housing assets & Household & Numeric & 126 & & & \\
\hline
\end{tabular}

Table 7. Correlation matrix between the dependent variables and covariates

\begin{tabular}{|c|c|c|c|c|c|c|c|c|}
\hline & Waz & RAI & Wealth & Edu & MBMI & Dratio & Magem & Mheight \\
\hline Waz & 1 & & & & & & & \\
\hline RAI & $-0.20 * *$ & 1 & & & & & & \\
\hline Wealth & $0.26^{* *}$ & -0.09 & 1 & & & & & \\
\hline Edu & $0.21 * *$ & -0.03 & $0.56^{* * *}$ & 1 & & & & \\
\hline MBMI & 0.01 & $-0.15^{*}$ & 0.04 & 0.14 & 1 & & & \\
\hline Dratio & $-0.18^{* *}$ & 0.07 & $-0.36 * * *$ & $-0.45^{* * *}$ & -0.00 & 1 & & \\
\hline Magem & $0.20^{* *}$ & -0.02 & $0.42^{* * *}$ & $0.64^{* * *}$ & $0.33^{* *}$ & $-0.49 * * *$ & 1 & \\
\hline Mheight & $0.23^{* *}$ & 0.08 & $0.27^{* *}$ & $0.28^{* *}$ & -0.07 & $-0.19 * *$ & $0.30 * *$ & 1 \\
\hline
\end{tabular}

livestocks, the indicator is particularly sensitive to those livelihood strategies the household may implement to increase its food security during times of crisis. 


\section{Econometric analysis}

We specify the following linear regression model:

$$
w_{i}=\beta_{0}+\beta_{1} R A I_{i}+\beta_{2} \text { mohalla }_{i}+\beta_{3} \text { MHeight }+u_{i}
$$

where, conditionally on the regressors, the disturbances $u_{i}$ are assumed to be zero mean and homoskedastic. We estimated the model by Ordinary Least Squared. ${ }^{24}$ The estimated equation, obtained on $n=101$ observations, is as follows:

$$
\text { waz }_{i}=-0.14-0.13 R A I_{i}+0.16 \text { mohalla }_{i}+0.07 \text { MHeight }+\hat{\mathrm{u}}_{\mathrm{i}}
$$

All estimated coefficients are statistically significant (model iii). The coefficient associated to Mheight shows that the height of the mother, which also reflect the socio-economic conditions of the household, has a beneficial effect on the nutritional status of children. Also, the location of the household within the village (mohalla) have important policy implications, as expected from the sampling strategy (Table 8).

The contribution of the present study regards in particular the statistical significant association of the autonomy of the mother, as measured by RAI, with the nutritional status of children. As previously discussed, such indicator stem from the CA and looks into the freedom of choice of the mother to move around freely in the community. The coefficient of the indicator is statistically significant at a $1 \%$ level. Thus, a unitary increase in autonomy of the mother is associated with a worsening of the nutritional status of the child. A possible explanation regards the environment in which the autonomy of women is inserted. Being a patriarchal society, it is conceivable that women who exert autonomy are few and they are subjected to a phenomenon of social exclusion. A possible argument in support of such interpretation is to be found in the correlation matrix between RAI and other covariates (Table 7). Despite such correlations are not statistically significant and quite weak, the negative sign of the correlation between the RAI and other basic indicator such as education, BMI, dratio,

\begin{tabular}{|c|c|c|c|}
\hline \multicolumn{4}{|c|}{ Dependent variable: waz. } \\
\hline & (i) & (ii) & (iii) \\
\hline RAI & $\begin{array}{l}-0.07 * * \\
(0.03)\end{array}$ & $\begin{array}{l}-0.09 * * \\
(0.03)\end{array}$ & $\begin{array}{l}-0.13^{* * *} \\
(0.03)\end{array}$ \\
\hline Wealth & $\begin{array}{l}0.24^{* * *} \\
(0.05)\end{array}$ & $\begin{array}{l}0.23^{* * *} \\
(0.05)\end{array}$ & \\
\hline Mohalla & & $\begin{array}{l}0.21 * * \\
(0.06)\end{array}$ & $\begin{array}{l}0.16^{* *} \\
(0.06)\end{array}$ \\
\hline Mheight & & & $\begin{array}{l}0.07^{* *} \\
(0.02)\end{array}$ \\
\hline \multicolumn{4}{|c|}{ Descriptive statistics } \\
\hline $\mathrm{n}$ & 130 & 129 & 101 \\
\hline Adjusted $\mathrm{R}^{2}$ & 0.13 & 0.20 & 0.25 \\
\hline Root MSE & 1.306 & 1.257 & 1.231 \\
\hline \multicolumn{4}{|l|}{ Tests } \\
\hline Reset & $\begin{array}{l}\mathrm{F}(3,124)=1.68 \\
p \text {-value }=0.174\end{array}$ & $\begin{array}{l}\mathrm{F}(3,127)=0.98 \\
p \text {-value }=0.403\end{array}$ & $\begin{array}{l}\mathrm{F}(3,94)=2.15 \\
p \text {-value }=0.09\end{array}$ \\
\hline Normality test & $\begin{array}{l}\chi^{2}(2)=1.07 \\
p \text {-value }=0.586\end{array}$ & $\begin{array}{l}\chi^{2}(2)=1.25 \\
p \text {-value }=0.536\end{array}$ & $\begin{array}{l}\chi^{2}(2)=0.31 \\
p \text {-value }=0.854\end{array}$ \\
\hline
\end{tabular}
indicate the plausibility of such direction for interpreting results.

24 We performed a misspecification test. Accordingly, RESET test does not reject the null hypothesis of no omitted variables due to an incorrect specification of the functional form at least at the 5\% significance level. Furthermore, we computed the Skewness-Kurtosis (Jarque-Bera) test for normality of the error term; in this case, the null hypothesis of normality is not rejected. 


\section{Conclusion}

The contribution of the Capability Approach to the discipline of Economics precisely lays on the underlying arguments supporting freedom of choice as focal variable for evaluating well-being, social welfare and related concepts. The present paper has aimed at fostering such perspective through an ad hoc case study addressing underweight in infant and young children not merely as due to a lack of resources, but also to a more subtle form of poverty, that is lack of freedom of choice. In order to overcome the challenge of unavailability of data and indicators collected in line with its tenets (e.g. participatory appraisal and focus group prior to the implementation of a 'traditional' survey design on a probabilistic random sample), we have therefore conducted a primary data collection in the village of Sankraud, which has been selected after a mapping study of the Government of India. The village, located in the district of Baghpat, in Uttar Pradesh, is simultaneously characterized by a flourishing agricultural sector, a patriarchal social structure and by ranking worst in terms of a composite indicator measuring anemia in women and underweight in children.

In such context, we have attempted at collecting capability-related data. Then, we have assessed the reliability and validity of the scale employed and constructed an indicator of relative autonomy in mobility as proxy of freedom of choice. Results indicate women who could actually be identified as autonomous are few in numbers. Furthermore, correlation analysis with the indicator of autonomy and socio-economic characteristics highlights poverty in different domains (e.g. space of resources and space of freedoms) do not overlap. Despite the analytical limitations particularly connected with the cross-sectional nature of the data and sample size, we run an econometric exercise to address the association of such capability-related indicator and the nutritional status of the child controlling for the location of the household within the village and the height of the mother as proxy for socio-economic conditions of the household.

Results point out in the patriarchal community, relative autonomy is negatively associated with the nutritional status of children, ceteris paribus. A simple question then arises. Should a local development program aim at decreasing such relative autonomy? From the CA's perspective, development interventions have to be directed towards increasing people's real opportunities for achieving valuable functionings as well as assuring that the conditions for freedom are enabling and just. Future research may consider, therefore, deepening the investigation of the concept of 'external capabilities', proposed in the literature by Foster and Handy (2009), for policy intervention aimed at simultaneously fostering the reduction of underweight as well as the dismissal of patriarchy. In particular, the further conceptual development of external capabilities, which refers to those 'abilities to function that are conferred by direct connection or relationship with another person', could not start from anywhere else than from its linkages with the basic assumption on human nature in terms of endaimonia. Thus, as defined in Bruni (2009), the accent would be on modeling "well-being in the sense of actualization of human potentials through intrinsically motivated activities in a context of interpersonal relationships". Future research may, therefore, benefit from the further theoretical development of the social nature of human agents as well as from deepening the measurement of relative autonomy in terms of intrinsically motivated activities.

\section{References}

Abell N.- Springer D. W. - Kamata A. (2009), Developing and validating rapid assessment instrument, Oxford University Press, Oxford.

Agarwal B.- Humphries J. - Robeyns I. (2005), Amartya Sen's work and ideas. A Gender Perspective, Routledge.

Alderman H. - Hoddinott J. - Kinsey B. (2006), Long term consequences of early child malnutrition, in Oxford Economic Papers, vol. 58, pp. 450-474.

Alkire S. (2005a), Subjective quantitative studies of human agency, in Social Indicators Research, vol. 74, pp. 217260.

Alkire S. (2005b), Why the Capability Approach?, in Journal of Human Development and Capabilities, Vol. 6, pp. 115135. 
Alkire S (2007), The Missing Dimensions of Poverty Data: An introduction, OPHI Working Paper No. 00.

Alkire S (2008), Concepts and Measures of Agency, OPHI Working Paper No. 9.

Alkire S. - Chiappero-Martinetti E. (2008), Towards a multidimensional measure of human agency, OPHI Working Paper No.12.

Bruni L. (2009) Happiness, in J. Peil and I. Van Staveren (eds.) Handbook of Economics and Ethics, Edward Elgar, Cheltenham, UK.

Clark D. A. (2009) Adaptation, Poverty and Well-Being: Some Issues and Observations with Special References to the Capability Approach and Development Studies, in Journal of Human Development and Capabilities, Vol. 10, pp. $21-42$.

Coast J. - Smith R. D. - Lorgelly P. (2008,) Welfarism, extra-welfarism and capability: The spread of ideas in health economics, in Social Science \& Medicine, vol. 67, pp. 1190-1198.

Comin F. - Qizilbash M. - Alkire S. (2008), The Capability Approach. Concepts, Measures and Applications, Cambridge University Press, Cambridge.

Cookson R. (2005), QALYs and the capability approach, in Health Economics, vol. 14, pp. 817-829.

Cronbach L. J. (1951), Coefficient alpha and the internal structure of tests, in Psychometrika, vol. 16, pp. 297-334.

Deaton A. - Drèze J. (2009), Food and Nutrition in India: Facts and Interpretations, in Economic and Political Week.ly, vol. 44, pp. 42-65.

Deci E. L. - Ryan R. M. (2000), The "what" and "why" of goal pursuit: human needs and the self-determination of behavior, in Psychological Inquiry, vol. 11, pp. 227-268.

Engle P.- Menon P. - Haddad L. (1999), Care and Nutrition: Concepts and Measurement, in World Development, vol. 27, pp. 1309-1337.

Filmer D. - Printchett L. H. (2001), Estimating wealth effects without expenditure data-or tears: an application to educational enrollments in States of India, in Demography, vol. 38, pp. 115-132.

Foster J. - Handy C. (2009) External Capabilities, in K. Basu and R. Kanbur (eds.), Arguments for a Better Word. Essays in Honor of Amartya Sen, Volume I, Ethics, Welfare and Measurement, Oxford University Press.

Gragnolati M. - Bredenkamp C. - Shekar M.- Das Gupta M. - Lee Y. L. (2005), India's Undernourished Children. A Call for Reform and Action, Health, Nutrition and Population Discussion Paper, World Bank.

Guttman L. (1945), A basis for analyzing test-retest reliability, in Psychometrika, vol. 10, pp. 255-282.

Haddad L. - Alderman H. - Appleton S. - Song L. - Yohannes Y. (2003), Reducing Child Malnutrition: How Far Does Income Growth Take Us, The World Bank Economic Review, vol. 17, pp. 107-131.

Haddad L. (2009), Lifting the Curse: Overcoming Persistent Undernutrition in India, IDS Bulletin, 40, pp. 1-8.

Ibrahim S. - Alkire S. (2007), Agency and Empowerment: A proposal for Internationally Comparable Indicators, in Oxford Development Studies, vol. 35, pp. 379-403.

Joe W. - Mishra U. S. - Navaneetham K. (2009), Inequalities in Childhood Malnutrition in India: Some Evidence on Group Disparities, in Journal of Human Development and Capabilities, vol. 10, pp. 417-430. 
Kumar A. K. S. (2007), Why are Levels of Child Malnutrition Not Improving?, in Economic and Political Weekly, vol. 41, pp. 1337-1345.

Law I. - Widdows H. (2008), Conceptualizing health: Insights from the Capability Approach, in Health Care Analysis, vol. 16, pp. 303-314.

Osmani S. - Sen. A. (2003), The hidden penalties of gender inequality: fetal origins of ill-health, in Economics and Human Biology, vol. 1, pp. 105-121.

Ramachandran P. (2007), Poverty nutrition linkages, in Indian Journal of Medical Research, vol. 126, pp. 249-261.

Ryan R. M. - Connell P. (1989), Perceived locus of causality and internalization. Examining reasons for acting in two domains, in Journal of Personality and Social Psychology, vol. 57, pp. 749-761.

Ryan R. M. - Deci E. L. (2000), Self-determination theory and the facilitation of intrinsic motivation, social development and well-being, in American Psychologist, vol. 55, pp. 68-78.

Ryan R. M. - Deci E. L. (2006), Self-Regulation and the Problem of Human Autonomy: Does Psychology Need Choice, Self-Determination, and Will?, in Joumal of Personality, vol. 74, pp. 1557-1585.

Sen A. (1985), Well-being, Agency and Freedom: The Dewey Lectures 1984, in Journal of Philosophy, vol. 82, pp. $169-221$.

Sen A. (1994), The formulation of Rational Choice, in The American Economic Review, vol. 84, pp.385-390.

Sen A. (1999), Commodities and Capabilities, Oxford India Paperbacks.

Sen A. (2002), Rationality and Freedom, Oxford India Paperbacks.

Smith L. C. - Haddad L. (2000), Explaining cbild malnutrition in developing countries. A cross-countries analysis, International Food Policy Research Institute.

Smith L. C. - Haddad L. (2001), How important is improving food availability for reducing child malnutrition in developing countries?, in Agricultural Economics, vol. 26, pp. 191-204.

Swaminathan M. S. (2009), Undernutrition in Infants and Young Children in India: A leadership Agenda for Action, in IDS Bulletin, vol. 40, pp. 103-110.

Uberoi P. (2009), Your law and custom. Legislating the family in India, Critical Quest, Gautam Printers, New Delhi.

World Bank (2006), Repositioning Nutrition as Central to Development. A strategy for Large-Scale Action, World Bank.

World Health Organization (2006), WHO Child Growth Standards, Length/ height-for-age, weight-for-age, weight-for-length, weight-for-height and body mass index-for-age, Methods and development, Department of Nutrition for Health and Development, World Health Organization.

World Health Organization (2010), WHO Anthro for Personal Computer Manual. Software for assessing growth and development of the world's children, Department of Nutrition for Health and Development, World Health Organization, Geneva. 


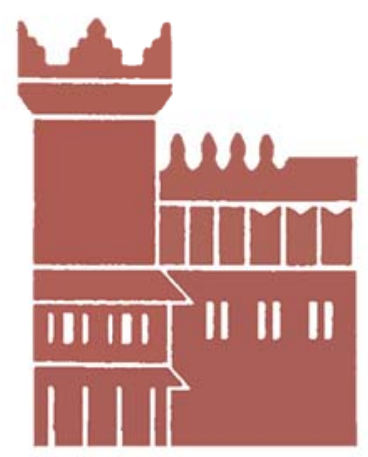

Alma Mater Studiorum - Università di Bologna DEPARTMENT OF ECONOMICS

Strada Maggiore 45

40125 Bologna - Italy

Tel. +39051 2092604

Fax +390512092664

http://www.dse.unibo.it 